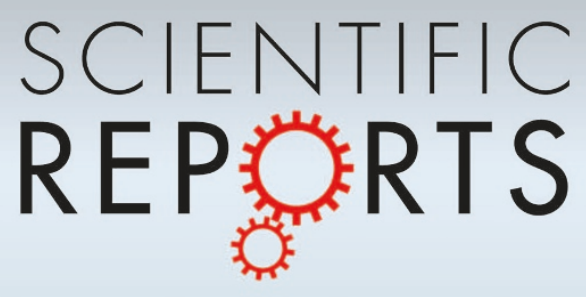

OPEN

SUBJECT AREAS:

CONSERVATION

ECOPHYSIOLOGY

BEHAVIOURAL ECOLOGY

EVOLUTIONARY ECOLOGY

Received

10 April 2013

Accepted

28 May 2013

Published

20 June 2013

Correspondence and requests for materials should be addressed to

J.D.B. (j.d.blount@ exeter.ac.uk) or K.E.P. (kate.plummer@bto. org)

* Current address: British Trust for Ornithology, The Nunnery, Thefford, Norfolk, IP24 2PU, UK.

\section{Winter food provisioning reduces future breeding performance in a wild bird}

\author{
K. E. Plummer ${ }^{1 *}$, S. Bearhop' ' D. I. Leech², D. E. Chamberlain ${ }^{3}$ \& J. D. Blount ${ }^{1}$
}

${ }^{1}$ Centre for Ecology and Conservation, College of Life \& Environmental Sciences, University of Exeter, Cornwall Campus, Penryn, Cornwall, TR 10 9EZ, UK, ${ }^{2}$ British Trust for Ornithology, The Nunnery, Thefford, Norfolk, IP24 2PU, UK, ${ }^{3}$ Dipartimento di Scienze della Vita e Biologià dei Sistemi, Università degli Studi di Torino, Via Accademia Albertina 13, 10123 Turin, Italy.

Supplementation of food to wild birds occurs on an enormous scale worldwide, and is often cited as an exemplar of beneficial human-wildlife interaction. Recently it has been speculated that winter feeding could have negative consequences for future reproduction, for example by enabling low quality individuals to recruit into breeding populations. However, evidence that winter feeding has deleterious impacts on reproductive success is lacking. Here, in a landscape-scale study of blue tits (Cyanistes caeruleus) across multiple years, we show that winter food supplementation reduced breeding performance the following spring. Compared to unfed populations, winter-fed birds produced offspring that weighed less, were smaller, and had lower survival. This impairment was observed in parents that had received fat only, or in combination with vitamin E, suggesting some generality in the mechanism by which supplementary feeding affected reproduction. Our results highlight the potential for deleterious population-level consequences of winter food supplementation on wild birds.

$\mathrm{V}$ ariation in food availability has profound effects on individual life-histories and the regulation of population dynamics ${ }^{1}$. The supply of food to animal populations is often perturbed through human activities. In particular, supplementation of food to wild animals is extensively applied as a conservation tool and often yields almost immediate increases in productivity ${ }^{2-5}$. However, studies of its downstream effects have highlighted some issues of concern such as biasing of primary sex ratios ${ }^{6}$, and increased disease transmission ${ }^{7}$. In addition to specific conservation projects, food supplementation to wildlife is in fact practiced on a far larger scale in gardens and backyards. For those species which use supplementary food in the UK, there is an estimated one feeder for every nine individual birds ${ }^{8}$, and similar levels of provisioning occur across much of the Western World ${ }^{9-12}$. Supplementary feeding of birds therefore represents an enormous perturbation of natural resource availability.

Food supplementation is predicted to benefit wild birds ${ }^{11}$, although a range of impacts seems possible. Recently it has been reported that food supplementation to birds whilst they are breeding can have immediate effects on diurnal activity pattern $s^{13}$ and result in reduced reproductive success ${ }^{14}$. However, it is unclear whether similarly deleterious effects may arise as a consequence of winter food supplementation. This is important because supplementary feeding is especially common during winter when there is an assumption that wild birds could benefit from being 'helped', yet there is considerable uncertainty about its impacts on future breeding performance ${ }^{10,15,16}$. Carry-over effects occur where events or life history decisions in one season or year influence events in a subsequent season or year ${ }^{15}$. Such carry-over effects are thought to be widespread and to have important consequences for fitness in wild populations of animals, although there have so far been few experimental demonstrations of their existence ${ }^{15}$. Food supplementation in winter can have almost immediate benefits for survival (e.g. ${ }^{17,18}$ ), and consequently it can result in increased recruitment and greater breeding densities the following spring ${ }^{19}$. However, only a single study to date has considered the effects of winter food supplementation on future reproductive success: winter feeding of blue tits (Cyanistes caeruleus) enabled birds to breed earlier and fledge more offspring during the following spring ${ }^{20}$. In contrast, it has been speculated that winter food supplementation could also have deleterious impacts. For example it may result in receipt of an unbalanced diet, or lead to negative density dependent processes and changes to the phenotypic structure of breeding populations as a consequence of increased over-winter survival ${ }^{10,16,21}$. Alternatively, food supplementation during winter could create an 'ecological trap' where birds receive inaccurate cues as to future natural food availability, and consequently make unsustainable investments in breeding ${ }^{16}$. If such effects are manifest they would be expected to cause reduced reproductive success at the population level.

Carry-over effects produced by winter supplementation might be influenced by the nutritional composition of foods. Items commonly provisioned to wild birds such as nuts, seeds and fats are rich in energy and lipophilic 


\begin{tabular}{|c|c|c|c|c|c|}
\hline \multirow[b]{2}{*}{ Breeding parameter } & \multirow[b]{2}{*}{ Treatment } & \multicolumn{3}{|c|}{ Year } & \multirow[b]{2}{*}{ Treatment mean } \\
\hline & & 2008 & 2009 & 2010 & \\
\hline Boxes occupied (\%) & $\begin{array}{c}\text { Unfed } \\
\text { Fat } \\
\text { Fat }+ \text { Vit E } \\
\text { Annual mean }\end{array}$ & $\begin{array}{l}37.7 \pm 5.9 \\
41.8 \pm 6.5 \\
43.7 \pm 14.9 \\
\mathbf{4 1 . 1} \pm \mathbf{5 . 1}\end{array}$ & $\begin{array}{l}38.9 \pm 11.8 \\
45.7 \pm 3.7 \\
44.3 \pm 10.7 \\
\mathbf{4 3 . 0} \pm \mathbf{4 . 8}\end{array}$ & $\begin{array}{l}47.2 \pm 8.2 \\
48.6 \pm 8.9 \\
53.0 \pm 0.3 \\
\mathbf{4 9 . 6} \pm \mathbf{3 . 6}\end{array}$ & $\begin{array}{l}41.3 \pm 4.7 \\
45.4 \pm 3.5 \\
47.0 \pm 5.5\end{array}$ \\
\hline Lay date $[1=1$ April] & $\begin{array}{c}\text { Unfed } \\
\text { Fat } \\
\text { Fat }+ \text { Vit E } \\
\text { Annual mean }\end{array}$ & $\begin{array}{l}27.6 \pm 1.2 \\
26.4 \pm 1.0 \\
26.0 \pm 1.0 \\
\mathbf{2 6 . 6} \pm \mathbf{0 . 6}\end{array}$ & $\begin{array}{l}24.3 \pm 0.9 \\
24.6 \pm 1.0 \\
25.4 \pm 1.0 \\
\mathbf{2 4 . 8} \pm \mathbf{0 . 6}\end{array}$ & $\begin{array}{r}29.6 \pm 0.9 \\
29.3 \pm 0.7 \\
31.7 \pm 1.0 \\
\mathbf{3 0 . 2} \pm \mathbf{0 . 5}\end{array}$ & $\begin{array}{l}27.3 \pm 0.6 \\
26.8 \pm 0.5 \\
28.0 \pm 0.6\end{array}$ \\
\hline Clutch size & $\begin{array}{c}\text { Unfed } \\
\text { Fat } \\
\text { Fat }+ \text { Vit E } \\
\text { Annual mean }\end{array}$ & $\begin{array}{r}8.0 \pm 0.2 \\
8.0 \pm 0.3 \\
8.5 \pm 0.3 \\
\mathbf{8 . 2} \pm \mathbf{0 . 2}\end{array}$ & $\begin{array}{l}8.5 \pm 0.3 \\
7.8 \pm 0.2 \\
7.7 \pm 0.3 \\
\mathbf{8 . 0} \pm \mathbf{0 . 2}\end{array}$ & $\begin{array}{l}8.3 \pm 0.2 \\
8.6 \pm 0.2 \\
7.6 \pm 0.2 \\
\mathbf{8 . 2} \pm \mathbf{0 . 1}\end{array}$ & $\begin{array}{l}8.3 \pm 0.2 \\
8.2 \pm 0.1 \\
7.9 \pm 0.1\end{array}$ \\
\hline Hatching success (\%) & $\begin{array}{c}\text { Unfed } \\
\text { Fat } \\
\text { Fat }+ \text { Vit E } \\
\text { Annual mean }\end{array}$ & $\begin{array}{r}91.5 \pm 2.3 \\
93.1 \pm 2.3 \\
93.1 \pm 2.0 \\
\mathbf{9 2 . 6} \pm \mathbf{1 . 3}\end{array}$ & $\begin{array}{l}87.2 \pm 2.6 \\
91.7 \pm 2.6 \\
90.6 \pm 2.3 \\
\mathbf{8 9 . 9} \pm \mathbf{1 . 4}\end{array}$ & $\begin{array}{l}91.0 \pm 2.6 \\
88.0 \pm 2.7 \\
95.1 \pm 1.5 \\
\mathbf{9 1 . 1} \pm \mathbf{1 . 4}\end{array}$ & $\begin{array}{l}89.9 \pm 1.4 \\
90.6 \pm 1.5 \\
92.9 \pm 1.2\end{array}$ \\
\hline
\end{tabular}

antioxidants such as vitamin $\mathrm{E}^{22,23}$. Daily energy acquisition is a key determinant of winter survival in small passerine species of birds, which can readily fall into negative energy balance when natural food is scarce ${ }^{17,24}$. However, over-reliance on supplemental energy-rich foods such as fats to the detriment of a balanced diet could be harmful $^{21}$. Furthermore, passerine species cannot store energy to any great extent. Therefore, with the exception of caching species, energy sequestered from the diet in winter is unlikely to fuel later reproduc$\operatorname{tion}^{25}$. Lipophilic antioxidants, on the other hand, may enhance health through effects on immunity and antioxidant defence ${ }^{22,26}$ and can be stored in large quantities in body tissues ${ }^{27,28}$. As such, it has been hypothesised that antioxidants in body storage could influence reproduction in later seasons or years ${ }^{29}$. In addition, the impacts of winter food supplementation on wild bird species are likely to be influenced by stochastic variation in natural food availability ${ }^{18,30}$. To detect such impacts therefore requires a landscape-scale experimental approach that encompasses multiple sites and years.

Using a three year experimental study conducted across nine woodland sites, we investigated the impacts of winter supplementation of energy- and antioxidant-rich foods on future reproduction in blue tits. Woodland populations of tits were randomly allocated to receive either fat $(\mathrm{n}=3)$, fat plus vitamin $\mathrm{E}(\mathrm{n}=3)$, or remained unfed as a control $(\mathrm{n}=3)$. The experiment was conducted over three years (2008-2010), and treatments were rotated amongst sites across years to control for any site-specific effects on breeding performance. Using woodland populations allowed greater control of the context and quantity of food provisioning than could have been achieved within an urban environment. Since natural food and breeding resources are anticipated to be more accessible to woodland birds ${ }^{31}$, our results are predicted to be a conservative estimate of the consequences of winter provisioning within a strictly urban landscape.

\section{Results}

There were no significant effects of winter food supplementation on nest box occupancy (binomial GLMM; $n=467$ out of 1038 boxes occupied over 3 years $\chi_{2}^{2}=3.17, P=0.21$ ). The timing of laying and clutch size also did not vary in response to food supplementation, as previously described in Plummer et al. (2013) ${ }^{21}$. Hatching success was marginally higher in fat plus vitamin E-fed populations compared to the other treatment groups (Table 1; binomial GLMM; $n=$ $362, \chi_{2}^{2}=5.44, P=0.066$ ). However, compared to unfed controls, parents that had been supplemented in the previous winter produced offspring that weighed less and were structurally smaller, and as a

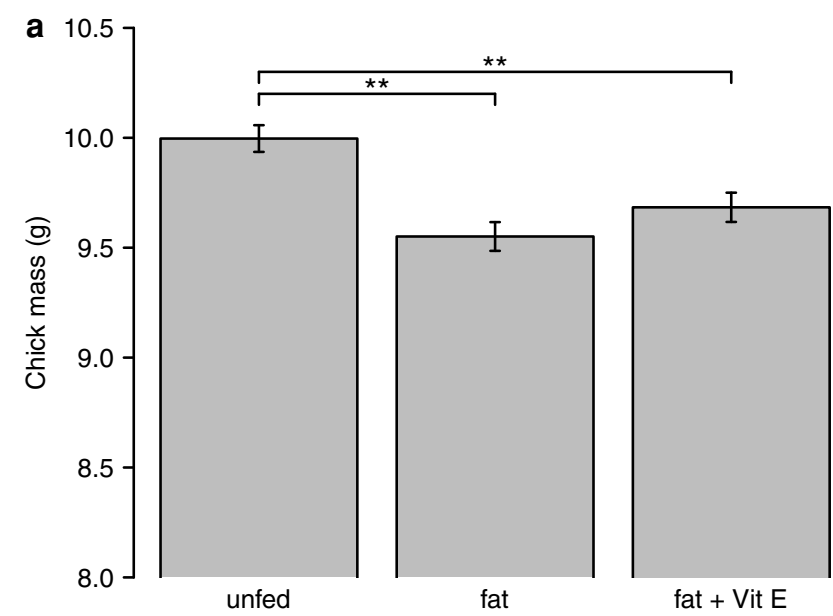

Winter feeding treatment

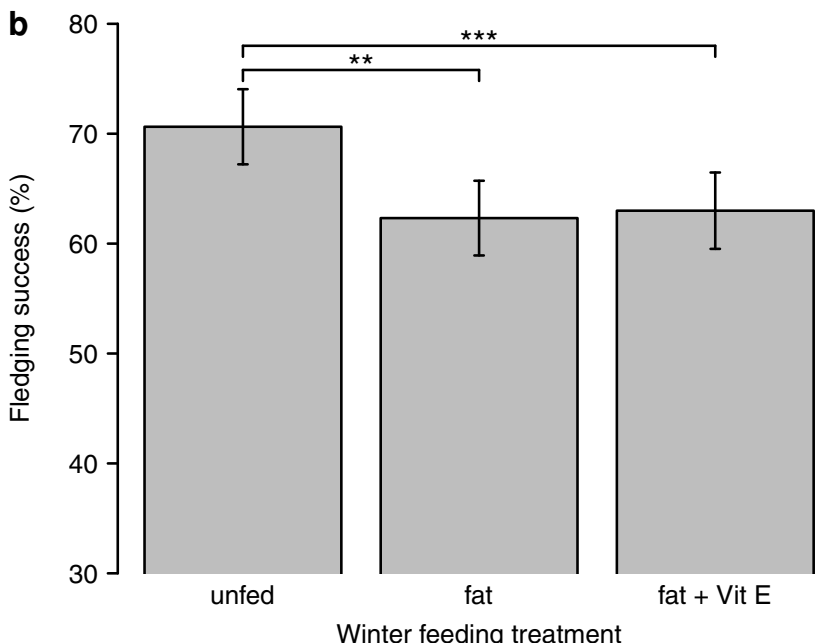

Figure $1 \mid$ Differences in (a) chick mass and (b) fledging success in response to winter feeding. Mean \pm s.e.m plotted using raw values. Significance of post-hoc pairwise comparisons shown, where $* *=P \leq 0.01$ and $* * *=P \leq 0.001$. 
Table 2 | Effects of winter food supplementation of parents on (a) chick mass, (b) chick head-bill length and (c) fledging success during the subsequent breeding season

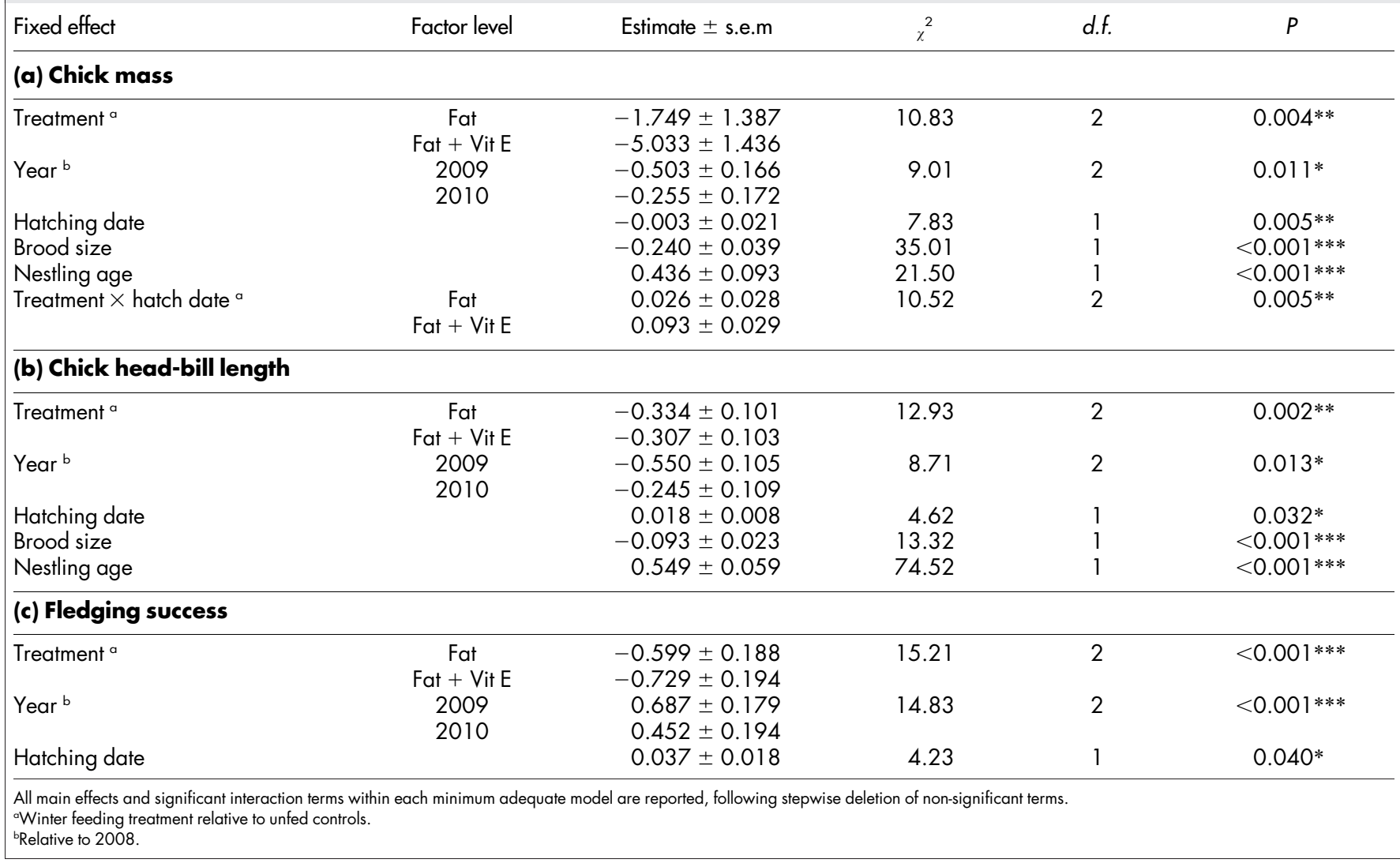

consequence fledged an average of $8 \%$ fewer offspring (Fig. 1, Table 2). Indeed, the body mass and head-bill length of chicks 12 days post-hatching strongly predicted their subsequent fledging success in all treatments and years (binomial GLMM, $n=288$; brood mean mass: $\chi_{1}^{2}=122.97, P<0.001$; brood mean head-bill length: $\chi_{1}^{2}$ $=70.61, P<0.001)$. These deleterious effects were irrespective of the specific type of food that was supplemented during the previous winter (Fig. 1, Table 2). Furthermore, there was significant annual variation in all breeding measures $\left(\chi^{2} \geq 8.71, P \leq 0.013\right)$ except nest box occupancy and hatching success $(P \geq 0.13)$. But the effects of treatment were not significantly influenced by year in any instance (treatment $\times$ year interaction: $P \geq 0.096$ ).

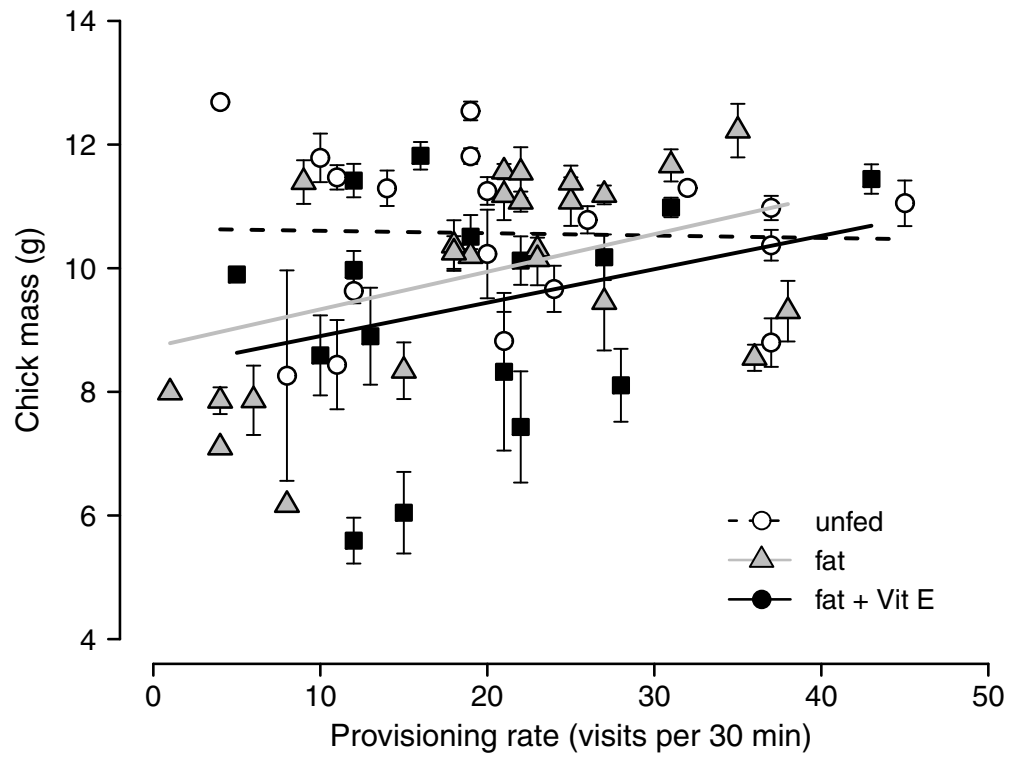

Figure $2 \mid$ Relationship between parental nest visit rate and chick mass. Brood means \pm s.e.m are plotted and lines fitted using parameter estimates from the minimum adequate model. Post-hoc comparisons showed that the relationship was significantly different for unfed parents compared to fat-fed $(P=0.046)$ and fat plus vitamin E-fed (fat + Vit E) parents $(P=0.017)$. 
We predicted that variation in offspring size and survival could result from differences in parental brood-rearing capacity carriedover from the winter feeding treatment. Therefore, we conducted a concurrent investigation to assess the extent to which variation in chick mass at day 12 was explained by parental nest visit rates during the first year of the study. Data were collected using video recordings at 59 nests across all nine woodlands and all three feeding treatments. Parental nest visit rates did not differ significantly amongst treatments (Poisson GLMM; $n=59, \chi_{2}^{2}=2.05, P=0.36$ ). However, nest visit rate positively predicted chick mass and this relationship differed amongst treatments (GLMM; $n=300$, treatment $\times$ nest visit rate interaction: $\left.\chi_{2}^{2}=8.11, P=0.017\right)$. There was no significant relationship between nest visit rate and the mass of chicks produced by unfed (control) parents, which were heavier on average (Fig. 1a). However, nest visit rate significantly predicted the mass of chicks produced by winter-fed parents of both food supplementation treatments (Fig. 2). Therefore, whilst winter-fed parents did not exhibit a reduction in nest visits per se, the quantity and/or nutritional value of delivered food items was clearly diminished.

\section{Discussion}

The results of this study cast doubt on the assumption that supplementary feeding of wild birds is invariably beneficial at the population level. Winter food supplementation resulted in reduced breeding success the following spring, several weeks after the provisioning of food had ended. Our results therefore provide an experimental demonstration of a carry-over effect, one of few such examples reported in a wild animal ${ }^{15}$. The capacity for within season food supplementation to influence reproduction in wild birds varies amongst sites and across years, for example in response to variation in natural food supply ${ }^{18,32-35}$. Such variance across years is clearly evident from the results of the present study (see Table 1). Yet, despite taking into account these notable sources of variation by conducting our research at nine woodlands and over three years, the overwhelming pattern which emerged was of deleterious impacts of winter food supplementation on future breeding performance.

Marginal increases in hatching success following vitamin E provisioning suggest that females were able to improve egg investment to some extent following increased antioxidant uptake in winter ${ }^{21,36}$. However, the negative effects of winter food supplementation on the weight, size and survival of chicks (Fig. 1), and on parental chick-rearing capacity (Fig. 2), suggests that initial investments made by fed parents could not be sustained post-hatching. Although conducted in a woodland environment, the difference in fledging success we report between fed and unfed populations resembles the level of variation in productivity observed between birds in urban and non-urban landscapes. Fledging success is on average $15.4 \%$ (95\% confidence range: $8.9-21.9 \%$ ) lower in urban compared to rural habitats for passerine bird species ${ }^{31}$. This difference has been attributed to the multiple costs associated urban living, including increased predation, greater disease transmission, fragmented habitat structure, road collision risk and reduced food availability ${ }^{31}$. Our results support the suggestion that supplementary feeding in urban gardens may also be a contributory factor ${ }^{14,31}$.

There are at least three possible explanations for our findings. First, winter feeding could have resulted in an unbalanced diet if birds heavily utilised supplementary food, and subsequently entered the breeding season in relatively poor nutritional condition. We are aware of only two previous studies which have experimentally investigated the effects of winter food supplementation on any aspect of future reproductive performance in birds. We recently reported that winter feeding with fat resulted in the production of eggs with relatively small yolks and reduced levels of carotenoid pigments early in the laying season, compared to birds supplemented with fat plus vitamin $\mathrm{E}$ or which were unfed ${ }^{21}$. In contrast, Robb et al. ${ }^{20}$ reported that winter feeding with peanuts led to earlier laying and increased fledging success in woodland populations of blue tits in a single year of study. One possible explanation for this difference is that the impacts of food supplementation on reproduction depend on the specific nutritional profile of foods. For example, sulphur-containing amino acids are potentially limiting for reproduction in birds, including tits ${ }^{37}$, although peanuts are a relatively poor source of these nutrients ${ }^{38}$. Dependency on supplemented fats, on the other hand, while being an excellent source of energy could result in an unbalanced diet with negative consequences for reproduction. We found that reproduction was impaired in populations that had been provisioned with fat, but also in populations which had received fat together with vitamin $\mathrm{E}$ - a potent antioxidant and immunostimulant $^{22,26}$. Therefore, negative effects of a diet rich in fats might override any benefits of antioxidant intake, although this possibility awaits study.

Second, through effects on survival and recruitment, winter food supplementation could have altered the phenotypic structure of breeding populations, such that they included increased numbers of individuals that had relatively low reproductive capacity. Third, winter food supplementation could have caused an ecological trap by encouraging birds to make unsustainable investments in reproduction, at localities which had insufficient natural food availability in spring $^{10,16}$. However, it is difficult to separate these possible mechanisms using breeding parameters at the population level as presented here. For example, we found no significant effect of winter food supplementation on nest box occupancy, as might be expected if breeding population density increased as a result of winter feeding either through greater survival or attraction to feeders. Although the abundance and utility of natural nesting sites is unknown and as such a true measure of breeding density is unavailable. To disentangle such carry-over effects and better understand the efficacy of bird feeding these possible mechanisms would ultimately require known individuals to be followed through winter and spring, which is almost impossible to do in the wild ${ }^{39}$.

In conclusion, this study has shown for the first time that winter food supplementation had deleterious consequences for future fledging success. Nevertheless, despite the evidence presented here, it would be premature to conclude that supplementary feeding is inevitably deleterious for wild birds. It would be particularly valuable to assess whether year-round food supplementation can alleviate negative effects of season-specific feeding. For example in the US, Florida scrub-jays living in suburban environments are believed to gain reproductive benefits due to the abundance and predictability of anthropogenic food sources ${ }^{40}$. Furthermore, how we judge the efficacy of food supplementation to wild birds must depend in part on whether impacts are assessed at the level of individuals or populations. For some individuals, the receipt of supplementary food may improve their lifetime reproductive success if they would otherwise have been unable to survive and recruit, or to reach a condition threshold necessary to breed. However, recruitment of such individuals might result in reduced mean productivity at the population level. Whether prolonged winter provisioning could bring about declines in the population sizes of wild birds in the long-term is an important question for future study. We note that there is no indication that overall numbers of blue tits in the UK have declined; in fact numbers have remained stable since $1995^{41}$. However, potential relationships between winter food supplementation and trends in population sizes of birds have not been investigated for any species. With garden bird feeding promoted as a method for conserving declining wild bird populations, these new insights suggest much more needs to be done to fully understand its impacts.

\section{Methods}

Study sites and experimental design. The study was conducted at nine deciduous woodlands in Cornwall, UK. Study woodlands averaged 10.7 hectares ( \pm 1.1 s.e.m) and were situated at least $2 \mathrm{~km}$ apart. The predominant tree species were oak (Quercus spp.), beech (Fagus sylvatica) and sweet chestnut (Castanea sativa). 
Woodlands were grouped into triplets according to their tree, understorey and ground cover species composition. Within sites, feeders and nest boxes were positioned at an equal density and distribution of $c a$. one feeder and four nest boxes per hectare. Given that woodlands were of a comparable size with nest boxes provided at equal densities, it is unlikely that our findings were influenced by densitydependent effects. The winter food supplementation experiment was conducted over three years from 2007 to 2009 (14 December - 4 March 2007/08; 18 November - 11 March 2008/09 and 2009/10), and potential carry-over effects on reproductive success were investigated during the subsequent springs, 2008-2010. In the first year of the study, each site within a triplet was randomly allocated to a feeding treatment: unfed (control), fat, or fat plus vitamin E. Treatments were rotated within triplets across years, so that every site received all three treatments over the course of the study. Therefore the potential confounding effect of variation in site quality was controlled for in the experimental design.

Winter food supplementation. All feeding stations were provisioned with a new $150 \mathrm{~g}$ fat ball every 10 days. Fat balls were produced 1-2 days in advance of provisioning, using solid vegetable fat (Crisp ' $n$ Dry, Princes Ltd., Liverpool, UK) and a small amount of yellow food colouring to increase food uptake by birds $(0.125 \mathrm{~mL}$ $100 \mathrm{~g}^{-1}$ fat; ASDA Natural Food Colouring, Asda Stores Ltd., Leeds). Fat balls for the fat plus vitamin E treatment group were supplemented with $\alpha$-tocopherol (T3251; Sigma-Aldrich, Dorset, UK) at a concentration of $100 \mathrm{mg} \mathrm{kg}^{-1}$ fat, a level equivalent to that found in peanuts ${ }^{42}$. Lipophilic antioxidants cannot be provisioned to birds without the use of fat or oil as a 'carrier', and such antioxidants are always co-acquired with lipids in natural foods ${ }^{43}$. All supplements were prepared using standardised methods ${ }^{21}$, and were predominantly utilised by the target species. Winter misting netting and stable isotope analysis confirmed the use of winter supplemented food by breeding birds.

Breeding success parameters. Nest boxes were inspected every 1-3 days from April to June to determine laying date, clutch size, brood size and fledging numbers. Hatching success was defined as the proportion of a clutch that hatched, and fledging success as the proportion of hatchlings that fledged. Morphometric measures were recorded for all surviving chicks at 12 days post-hatching ( \pm 1 day; mean chick age \pm s.e.m: $12.19 \pm 0.02, n=1706$, brood $n=319)$. Body mass $( \pm 0.1 \mathrm{~g})$ was recorded using an electronic balance and head - bill length $( \pm 0.05 \mathrm{~mm})$ measured twice with dial callipers then averaged ${ }^{44}$.

Parental visit rates. Parental visit rates to nests were recorded on day 11 ( \pm 1 day; $n=$ 59) of the nestling phase during the first breeding season (2008). Nest boxes were filmed for 30 min using a Sony DCR - HC37E Handycam at 0630 GMT or 0830 GMT. Chick age and filming time did not differ significantly between treatment groups (GLMs: $P>0.15$ ). Parental visit rate, defined as the number of visits per $30 \mathrm{~min}$, was extracted from video playbacks. The sex of parents could not be distinguished from the video recordings, and therefore nest mean visit rates were calculated.

Statistical analyses. All statistical analyses were conducted using R version $2.12 .2^{45}$ Data were analysed using general/generalised mixed effects models (GLMMs) and backwards stepwise deletions of non-significant terms, with alpha set at 0.05 . Hatching and fledging success data were fitted using binomial errors and parental nest visit rates using Poisson errors, after checking for overdispersion. Remaining analyses were completed using a Gaussian error distribution, and the normality and homoscedasticity of residuals were checked prior to model simplification. For analysis of nest box occupancy, lay date, clutch size, hatching and fledging success, nest box identity nested within woodland site was specified as the random term to control for pseudoreplication. Brood identity was included as a random term, nested within nest box identity, in analyses of chick phenotypes to control for nonindependence of chicks within broods. Nest box identity was excluded from analyses involving parental nest visit rate, as boxes were only used once within a given year. Winter food supplementation treatment, year and lay/hatching date were included as explanatory variables in all relevant models. Brood size at hatching and chick age at sampling were additionally controlled for in chick analyses. All two-way interactions involving treatment were fitted in all models. For post-hoc testing, ANOVA was used to compare the minimum GLMM model with replicate models in which two treatment groups under comparison were paired. A total of 467 boxes were nested in by blue tits over the study period. Lay date analysis included all clutches, but for all subsequent analyses clutches with laying breaks $>2$ days $(n=23)$ and/or abandoned prior to incubation $(n=32)$ were excluded. Only hatched clutches were considered in hatching and fledging success analyses $(n=362)$. Broods abandoned within one day of sampling activities, or which could not be regularly monitored due to time constraints $(n=28)$ were excluded from chick size and fledging analyses. These data filters were not biased amongst treatment groups $(P>0.11)$.

1. Lack, D. The Natural Regulation of Animal Numbers. (Oxford University Press, 1954).

2. Armstrong, D. P., Castro, I. \& Griffiths, R. Using adaptive management to determine requirements of re-introduced populations: the case of the New Zealand hihi. J. Appl. Ecol. 44, 953-962 (2007).
3. Oro, D., Margalida, A., Carrete, M., Heredia, R. \& Donázar, J. A. Testing the goodness of supplementary feeding to enhance population viability in an endangered vulture. PLoS One 3, e4084 (2008).

4. Schoech, S. J. et al. Food supplementation: A tool to increase reproductive output? A case study in the threatened Florida Scrub-Jay. Biol. Conserv. 141, 162-173 (2008).

5. López-Bao, J. V., Palomares, F., Rodríguez, A. \& Delibes, M. Effects of food supplementation on home-range size, reproductive success, productivity and recruitment in a small population of Iberian lynx. Anim. Conserv. 13, 35-42 (2009).

6. Clout, M. N., Elliott, G. P. \& Robertson, B. C. Effects of supplementary feeding on the offspring sex ratio of kakapo: a dilemma for the conservation of a polygynous parrot. Biol. Conserv. 107, 13-18 (2002).

7. Blanco, G., Lemus, J. A. \& García-Montijano, M. When conservation management becomes contraindicated: impact of food supplementation on health of endangered wildlife. Ecol. Appl. 21, 2469-2477 (2011).

8. Davies, Z. G. et al. A national scale inventory of resource provision for biodiversity within domestic gardens. Biol. Conserv. 142, 761-771 (2009).

9. Lepczyk, C. A., Mertig, A. G. \& Liu, J. Assessing landowner activities related to birds across rural-to-urban landscapes. Environ. Manage. 33, 110-125 (2004).

10. Jones, D. N. \& Reynolds, S. J. Feeding birds in our towns and cities: a global research opportunity. J. Avian Biol. 39, 265-271 (2008).

11. Toms, M. P. \& Sterry, P. Garden Birds and Wildlife. (AA, 2008).

12. O'Leary, R. \& Jones, D. N. The use of supplementary foods by Australian magpies (Gymnorhina tibicen): implications for wildlife feeding in suburban environments. Austral Ecol. 31, 208-216 (2006).

13. Saggese, K., Korner-Nievergelt, F., Slagsvold, T. \& Amrhein, V. Wild bird feeding delays start of dawn singing in the great tit. Anim. Behav. 81, 361-365 (2011)

14. Harrison, T. et al. Does food supplementation really enhance productivity of breeding birds? Oecologia 164, 311-320 (2010).

15. Harrison, X. A., Blount, J. D., Inger, R., Norris, D. R. \& Bearhop, S. Carry-over effects as drivers of fitness differences in animals. J. Anim. Ecol. 80, 4-18 (2011)

16. Robb, G. N., McDonald, R. A., Chamberlain, D. E. \& Bearhop, S. Food for thought: supplementary feeding as a driver of ecological change in avian populations. Front. Ecol. Environ. 6, 476-484 (2008).

17. Brittingham, M. C. \& Temple, S. A. Impacts of supplemental feeding on survival rates of black-capped chickadees. Ecology 69, 581-589 (1988).

18. Kallander, $H$. The effects of provision of food in winter on a population of the great tit Parus major and the blue tit P. caeruleus. Ornis Scand. 12, 244-248 (1981).

19. Newton, I. Population limitations in birds. (Academic Press, 1998).

20. Robb, G. N. et al. Winter feeding of birds increases productivity in the subsequent breeding season. Biol. Lett. 4, 220-223 (2008).

21. Plummer, K. E., Bearhop, S., Leech, D. I., Chamberlain, D. E. \& Blount, J. D. Fat provisioning in winter impairs egg production during the following spring: a landscape-scale study of blue tits. J. Anim. Ecol., 673-682 (2013).

22. Catoni, C., Peters, A. \& Schaefer, H. M. Life history trade-offs are influenced by the diversity, availability and interactions of dietary antioxidants. Anim. Behav. 76, 1107-1119 (2008)

23. Venkatachalam, M. \& Sathe, S. K. Chemical composition of selected edible nut seeds. J. Agr. Food Chem. 54, 4705-4714 (2006).

24. Koivula, K., Orell, M., Rytkonen, S. \& Lahti, K. Fatness, sex and dominance: seasonal and daily body mass changes in willow tits. J. Avian Biol. 26, 209-216 (1995).

25. Drent, R. H. \& Daan, S. The prudent parent - energetic adjustments in avian breeding. Ardea 68, 225-252 (1980).

26. Monaghan, P., Metcalfe, N. B. \& Torres, R. Oxidative stress as a mediator of life history trade-offs: mechanisms, measurements and interpretation. Ecol. Lett 12, 75-92 (2009)

27. Surai, P. F. Natural Antioxidants in Avian Nutrition and Reproduction. 2 edn, (Nottingham University Press, 2007).

28. Negro, J. J., Figuerola, J., Garrido, J. \& Green, A. J. Fat stores in birds: an overlooked sink for carotenoid pigments? Funct. Ecol. 15, 297-303 (2001).

29. Metzger, B. \& Bairlein, F. Fat stores in a migratory bird: a reservoir of carotenoid pigments for times of need? J. Comp. Phys. B 181, 269-275 (2011).

30. Lambrechts, M. M. et al. Habitat quality as a predictor of spatial variation in blue tit reproductive performance: a multi-plot analysis in a heterogeneous landscape. Oecologia 141, 555-561 (2004).

31. Chamberlain, D. E. et al. Avian productivity in urban landscapes: a review and meta-analysis. Ibis 151, 1-18 (2009).

32. Arnold, T. W., Alisauskas, R. T. \& Ankney, C. D. Egg composition of American coots in relation to habitat, year, laying date, clutch size, and supplemental feeding. Auk 108, 532-547 (1991)

33. Svensson, E. \& Nilsson, J.-Å. Food-supply, territory quality, and reproductive timing in the blue tit (Parus caeruleus). Ecology 76, 1804-1812 (1995).

34. Norris, K. Seasonal-variation in the reproductive success of blue tits - an experimental-study. J. Anim. Ecol. 62, 287-294 (1993)

35. Nager, R. G., Ruegger, C. \& Noordwijk, A. J. V. Nutrient or energy limitation on egg formation: a feeding experiment in great tits. J. Anim. Ecol. 66, 495-507 (1997).

36. Møller, A. P., Karadas, F. \& Mousseau, T. A. Antioxidants in eggs of great tits Parus major from Chernobyl and hatching success. J. Comp. Phys. B 178, 735-743 (2008). 
37. Houston, D., Donnan, D. \& Jones, P. Use of labelled methionine to investigate the contribution of muscle proteins to egg production in zebra finches. J. Comp. Phys. B 165, 161-164 (1995).

38. Basha, S. M. Deposition pattern of methionine-rich protein in peanuts. J. Agr. Food Chem. 39, 88-91 (1991).

39. Perrins, C. M. British Tits. (Collins, 1979).

40. Schoech, S. J., Bowman, R. \& Reynolds, S. J. Food supplementation and possible mechanisms underlying early breeding in the Florida Scrub-Jay (Aphelocoma coerulescens). Horm. Behav. 46, 565-573 (2004).

41. British Trust for Ornithology. GardenBird Watch Annual Results 2011. (British Trust for Ornithology Press, Thetford, 2011).

42. Chun, J., Lee, J. \& Eitenmiller, R. R. Vitamin E and oxidative stability during storage of raw and dry roasted peanuts packaged under air and vacuum. J. Food Sci. 70, C292-C297 (2005).

43. Blount, J. D. et al. Carotenoids and egg quality in the lesser black-backed gull Larus fuscus: a supplemental feeding study of maternal effects. P. Roy. Soc. Lond. B. 269, 29-36 (2002).

44. Redfern, C. P. F. \& Clark, J. A. Ringers' Manual. (BTO, 2001).

45. R: A language and environment for statistical computing. R Foundation for Statistical Computing, Vienna, Austria (ISBN 3-900051-07-0, URL http:// www.R-project.org/, 2011).

\section{Acknowledgements}

We thank the many landowners and fieldworkers who made this research possible, A. Wilson for video analysis of parent provisioning data, and N. Carter for logistical support. We are grateful to K.J. Gaston, T. Tregenza and the anonymous reviewers for helpful comments on the manuscript. This work was funded by a Natural Environment Research Council (NERC) CASE studentship (to K.E.P., J.D.B., S.B. and D.E.C.), a Royal Society Research Fellowship (to J.D.B.), the BTO and Gardman Ltd.

\section{Author contributions}

K.E.P., S.B., D.I.L., D.E.C. and J.D.B. designed the research. K.E.P. and J.D.B. wrote the first $\mathrm{draft}$, and the manuscript was reviewed by all the authors. K.E.P. collected and analysed the data.

\section{Additional information}

Competing financial interests: The authors declare no competing financial interests.

How to cite this article: Plummer, K.E., Bearhop, S., Leech, D.I., Chamberlain, D.E. \& Blount, J.D. Winter food provisioning reduces future breeding performance in a wild bird. Sci. Rep. 3, 2002; DOI:10.1038/srep02002 (2013).

\footnotetext{
(c) (1) $\Theta$ This work is licensed under a Creative Commons Attribution-

NonCommercial-NoDerivs 3.0 Unported license. To view a copy of this license, visit http://creativecommons.org/licenses/by-nc-nd/3.0
} 